\title{
A Probabilistic Model for the Fallout Area of Single Glazing under Radiant Heat Exposure
}

\author{
DANIEL WONG ${ }^{1}$, KAIYUAN LI $^{2}$ and MICHAEL SPEARPOINT ${ }^{3}$ \\ ${ }^{1}$ Olsson Fire \& Risk, \\ Melbourne, Australia \\ ${ }^{2}$ State Key Lab of Fire Science, \\ University of Science and Technology of China, \\ Hefei 230027, China \\ ${ }^{3}$ Department of Civil and Natural Resources Engineering, \\ University of Canterbury \\ Christchurch, New Zealand
}

\begin{abstract}
This paper investigates the area of window fallout behaviour of $4 \mathrm{~mm}$ and $6 \mathrm{~mm}$ thick single glazed ordinary float type glass exposed to a constant radiant heat. Regular rubber beadings and non-standard ceramic fibre beadings were used to mount the $525 \mathrm{~mm}$ square glass samples in commercial aluminium window frames. A total of 117 experiments were carried out where the area of glass fallout was recorded as a function of time. The average heat fluxes which the glass samples were exposed to ranged from $13 \mathrm{~kW} / \mathrm{m}^{2}$ to $58 \mathrm{~kW} / \mathrm{m}^{2}$. The lowest heat flux that is needed for fallout occurrence is found to be $20 \mathrm{~kW} / \mathrm{m}^{2}$ for $4 \mathrm{~mm}$ thick glass and $28 \mathrm{~kW} / \mathrm{m}^{2}$ for $6 \mathrm{~mm}$ thick glass. The fallout behaviour of glass was quantified with an exponential distribution function and a probabilistic area of glass fallout prediction model for $4 \mathrm{~mm}$ and $6 \mathrm{~mm}$ thick glass is developed from the experimental results.
\end{abstract}

KEYWORDS: glass, fallout, probabilistic, compartment fires.

\section{NOMENCLATURE LISTING}

$a_{1} \quad$ parameter in probabilistic model

$b_{1} \quad$ parameter in probabilistic model

$P_{\text {fallout }}$ probability of glass fallout

$t_{1} \quad$ time after initial crack or fracture $(\mathrm{s})$

\author{
Greek \\ $\lambda \quad$ coefficient of distribution function
}

\section{INTRODUCTION}

When a fire breaks out in a compartment it will potentially transient from a growth phase to a fully developed phase. One factor which will influence the development of the fire is the air supply due to the ventilation $[1,2]$. The ventilation to a compartment may be limited unless there is an adequate area of open vents to allow air from outside the compartment to enter and sustain the fire until it reaches the fully developed phase [3]. The open vents may exist in the form of doors, windows or other penetrations [4]. Open vents can be created from closed windows if glass panes in the windows fracture and fallout after being exposed to the fire.

Babrauskas [5] has summarised the experimental work carried out by various researchers. Much of the previous work has addressed the characteristics of glass fracture but not the fallout behaviour of the glass mounted in windows frames. Keski-Rahkonen [6] discussed that for regular float glass (the majority of which is soda-lime glass), the time to first facture and the total destruction of the glass pane can be assumed to be the same for many purposes. Skelly et al. [7] carried out a series of experiments using a $1.5 \mathrm{~m} \times 1.2 \mathrm{~m}$ $\times 1.0 \mathrm{~m}$ compartment. The experiments were carried out with $2.4 \mathrm{~mm}$ thick $\times 280 \mathrm{~mm} \times 500 \mathrm{~mm}$ soda glass windows which were mounted in a $360 \mathrm{~mm} \times 560 \mathrm{~mm}$ aluminium frame that was fitted on one side of the compartment. Eleven experiments where carried out such that a $25 \mathrm{~mm}$ wide protected edge was maintained around the perimeter of the pane and six experiments where the whole pane was exposed. In all of the experiments, it was reported that the entire pane of glass was fully submerged in the hot gas layer of the fire within the first $10 \mathrm{~s}$. Skelly et al. reported ten cases of window collapse out the total eleven 
experiments carried out for the edge-protected window experiments while no glass breakage was reported for the remaining one experiment. They noted that in the majority of these ten cases more than half of the window was removed from the frame but no further details are given. Three cases of window glass removal because of cracking where noted in the edge-unprotected experiments but none of the areas exceeded $3 \mathrm{~cm}^{2}$. The experimental work carried out by Harada et al. [8] with $3 \mathrm{~mm}$ thick float glass showed that generally small pieces of glass will fallout at the same time as the initial crack while in some tests large pieces of glass fell out successively after the first fracture. Similarly the progressive fallout behaviour of single glazing was also observed in the experimental work carried out by Shields et al. [9, 10]. Pope and Bailey [11] noted that previous studies on glass breakage had data sets which are too small for a meaningful statistical analysis but these studies reveal the probabilistic nature of glass breakage.

The fracture and fallout behaviour of glazing in windows is of interest to fire modellers as the dynamics of the fire can change dramatically depending on the ventilation conditions. For example Parry et al. [12] developed a glass fracture model using the heat transfer model proposed by Sincaglia and Barnett [13] and the fracture criterion by Pagni and Joshi [14] which was then incorporated into the BRANZFIRE two-zone model [15]. However including a glass fallout algorithm into the successor to BRANZFIRE, known as BRISK [16], has not been feasible as yet. Hietaniemi [17] has developed a model for the probability of glass fracture and fallout. The model provides a pragmatic approach to a very complex problem but appears to give reasonable outcomes in terms of the times and temperatures related to multiple cracks when assessed against various experiments reported in the literature.

The purpose of this paper is to present additional data for glass fallout as a function of time when exposed to constant and relatively uniform radiant heat and then to investigate the likelihood of different areas of single glazed glass fallout. An experimental approach is used which involved exposing 117 windows to a radiant heat source to enable the fallout behaviour of single glazing to be quantified in a probabilistic manner.

\section{EXPERIMENTS}

The experimental work was conducted at the University of Canterbury fire laboratory which placed a limit on the size of the fire and corresponding window dimensions. A plan of the layout of the experiment setup is shown in Fig. 1. The setup consisted of the main frame which was mounted on wheels in guide rails so elements could be easily moved, the window frame incorporating the glass sample, a radiation shield which separated the glass sample from the fire prior to each experiment, a gas burner and a spark igniter. The incident radiant heat was generated using a $350 \mathrm{~kW}$ gas burner with pre-defined distances between the centre of the burner and the exposed face of the glass used to vary the incident flux values. A metal deflector was placed behind the gas burner to stabilise the flame and minimise the likelihood of impingement on the glass samples. The setup is similar to that used by Harada et al. [8] although they used a propane fuelled radiant panel to generate the incident heat flux rather than a gas burner flame used in this study.

The glass samples used in the experiments were ordinary float glass panes with thicknesses of $4 \mathrm{~mm}$ and $6 \mathrm{~mm}$. The size of each glass pane was $525 \mathrm{~mm} \times 525 \mathrm{~mm}$. The glass panes were cut by the supplier and the edges were ordered as clean cut i.e. the edges were not polished. A four-point bending test on $210 \mathrm{~mm}$ long $\times 30 \mathrm{~mm}$ wide samples of the glass determined the breaking strength as $64 \mathrm{MPa} \pm 15 \mathrm{MPa}$ and the modulus of elasticity as 76.5 $\pm 4.0 \mathrm{GPa}$ comparable to Skelly et al.’s $70 \mathrm{GPa} \pm 10 \%$ [7].

Commercial aluminium window frames were utilised since these are commonly used in modern buildings as well as being non-combustible therefore reusable for multiple experiments. The aluminium frames were able to withstand sufficiently high temperatures without distortion. Figure 1(c) presents the configuration of the window frame. The area of the glass sample exposed to the radiant heat was $500 \mathrm{~mm} \times 500 \mathrm{~mm}$ once mounted in the window frames thus resulting in a protected edge boundary of $25 \mathrm{~mm}$ (12.5 mm at each side) similar to Skelly et al. [7]. Grids of $50 \mathrm{~mm} \times 50 \mathrm{~mm}$ were drawn on the surface of each glass sample using a permanent marker pen to allow the area of fallout in the glass to be measured. The grids were drawn on the unexposed face of the glass since direct exposure to the radiant heat caused the marking to evaporate quickly. 
Rubber and ceramic fibre beadings were used to mount the glass panes into the aluminium frames. The rubber beadings consisted of regular beadings which are typically used for glazing purposes. The beading is specific to the thickness of the glass pane so two beading sizes were used to glaze the $4 \mathrm{~mm}$ and $6 \mathrm{~mm}$ thick glass panes. However, the ceramic fibre beading in rope form is not a standard beading used in window glazing. The rope consisted of three pre-twisted strands twisted together. The ceramic fibre beading was used to investigate whether the fallout behaviour of the glazing would be influenced by the type of beading used to glaze the window. In particular it was found that the rubber beading melted and/or ignited during exposure so that it potentially affected the fallout characteristics.

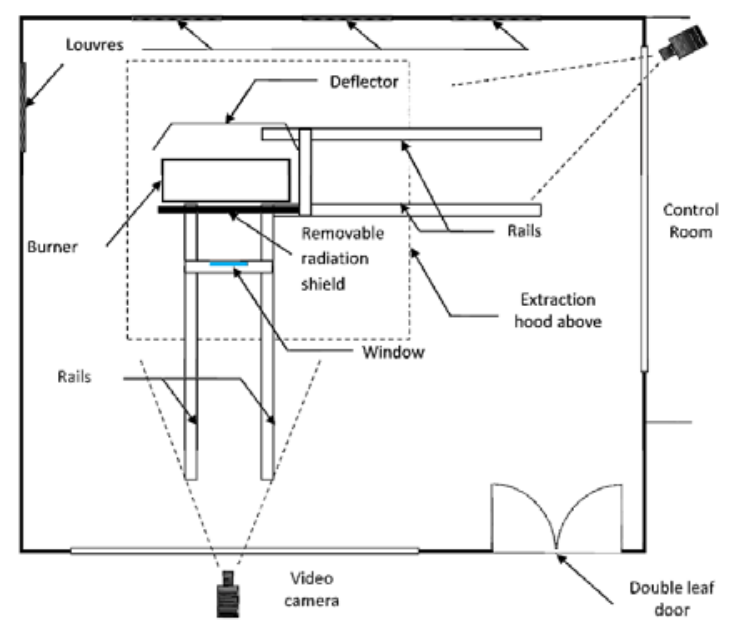

(a)

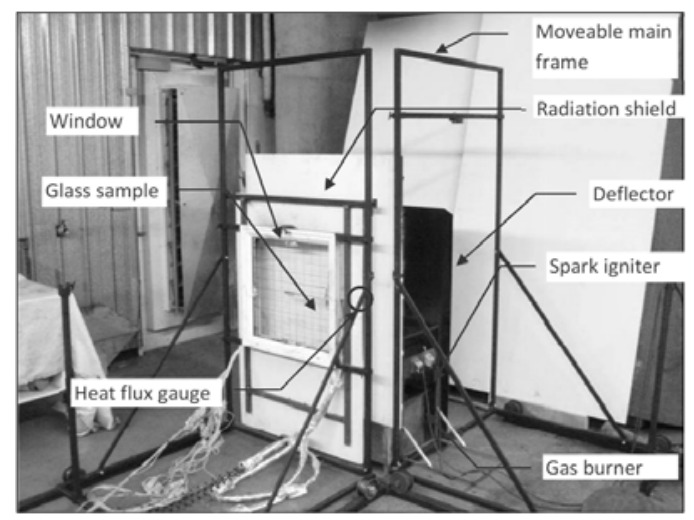

(b)

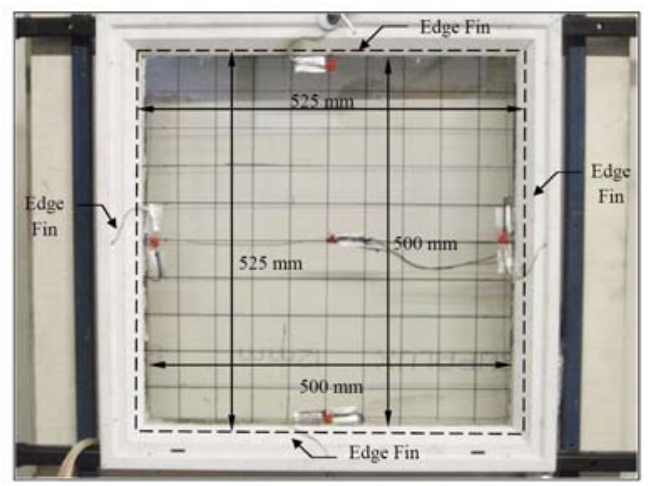

(c)

Fig. 1. Experimental setup: (a) plan view; (b) photograph; (c) aluminium frame and glass with $50 \mathrm{~mm} \times$ $50 \mathrm{~mm}$ grids. 
Incident heat flux, time to first fracture and the progressive area of glass fallout were measured in each experiment while glass surface temperature and strain measurements were conducted in selected experiments. The location of thermocouples and thermal strain gauges are shown in Fig. 2. The strain measurements are not reported here but are available in the associated research report [18].

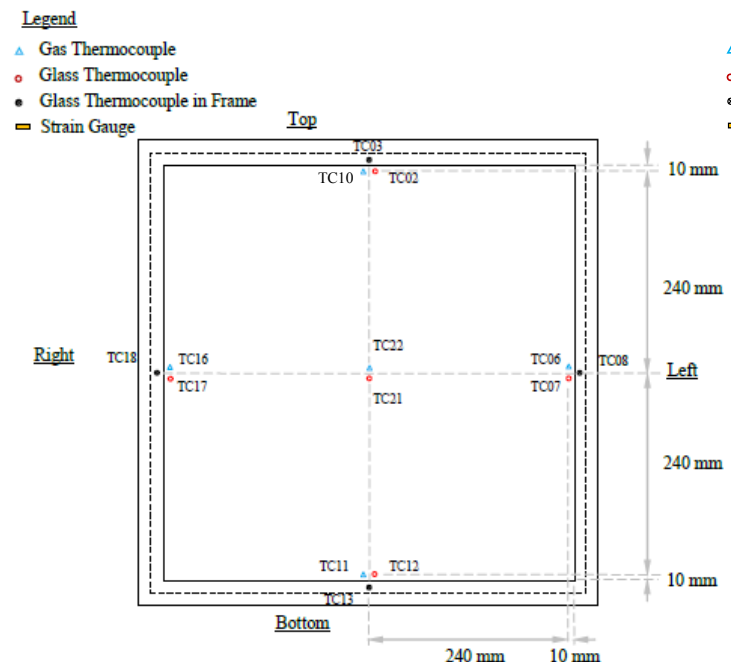

(a)
Legend

$\Delta$ Gas Thermocouple

- Glass Thermocouple

- Glass Thermocouple in Frame

๑ Strain Gauge

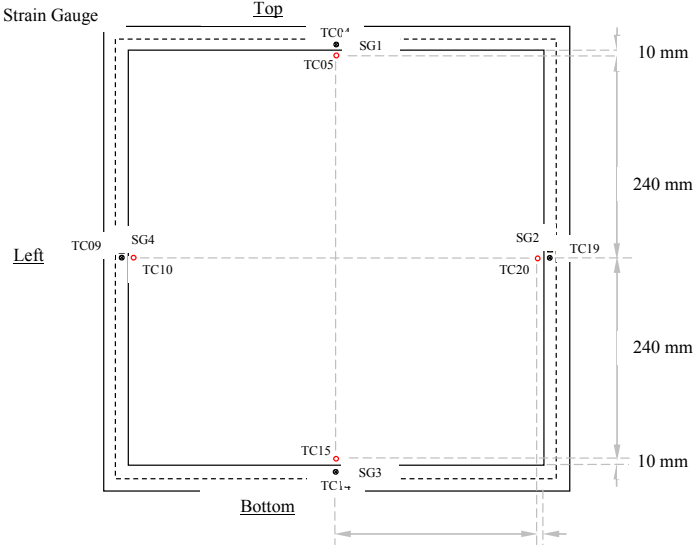

(b)

Fig. 2. Location of thermocouples and strain gauges: (a) Exposed face; (b) Unexposed face.

The thermocouples used in the experiments were Type K, 24 gauge devices. Thermocouples on the glass surface were attached using high temperature resistant adhesive. The glass thermocouples in the window frame on the unexposed face were not applied with the adhesive and were left exposed while touching the glass. Thermocouples were not attached to the glass for all of the experiments as there was a concern that they may influence the fallout characteristics by restraining fragments.

A $0-100 \mathrm{~kW} / \mathrm{m}^{2}$ calibrated Schmidt-Boelter type gauge was used to measure the heat flux in each experiment. The heat flux gauge was constantly cooled by running water supplied through flexible hoses. A heat flux distribution test was conducted using a dummy sample prior to the actual glass experiments where the radiant heat fluxes at 10 different locations were measured as shown in Fig. 3. The gauge was flushmounted at each measuring position through holes in a vertical sheet of calcium silicate board. During the actual glass experiments, the heat flux gauge was set at Point 10 (i.e. offset from the glass pane) to monitor the heat flux and ensure there were no major changes in heat flux compared to the distribution test.

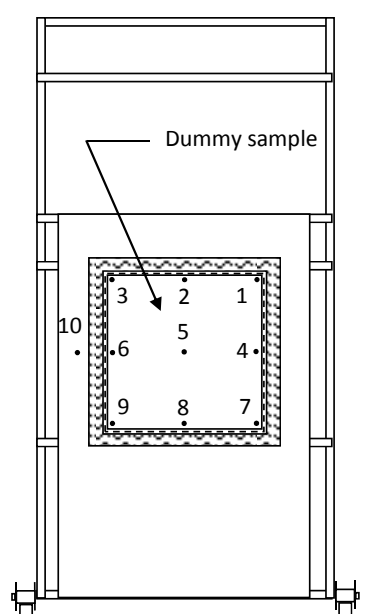

(a)

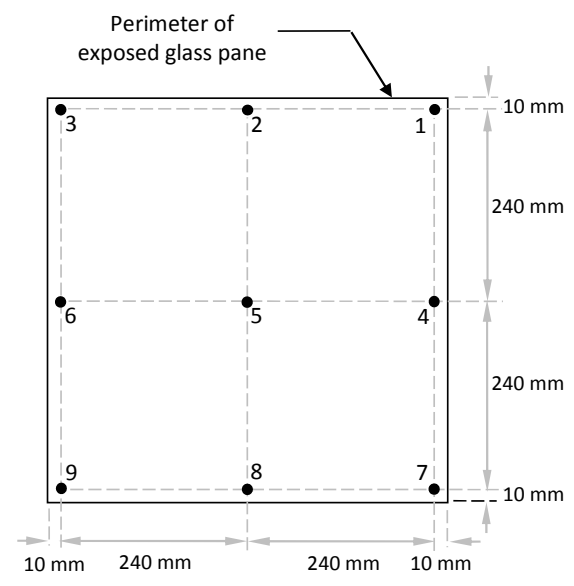

(b)

Fig. 3. Locations of heat flux gauge in radiant heat flux distribution experiment (viewed from burner side). 
Visual recordings of the experiments were carried out using two Canon XM2 digital video camcorders placed at two locations behind the protective glass windows outside the fire laboratory. A digital camera was also used to take still photos during each experiment. Data logging software was used to record the thermocouple, heat flux gauge and strain gauge measurements. During each experiment the time to initial glass fracture was recorded followed by the time at which any glass fallout occurred.

For each test the burner flame was allowed to stabilise for $30 \mathrm{~s}$ after which the radiation shield was removed to expose the pre-positioned window. The windows were exposed to the burner flame for approximately $630 \mathrm{~s}$. The $630 \mathrm{~s}$ exposure time was chosen based on four trial experiments carried out prior to the main glass fallout experiments. During the trial experiments, glass fallout (if any) ceased after approximately 5 minutes of exposure so that the $630 \mathrm{~s}$ exposure time provides for $5 \mathrm{~min}$ with an additional allowance. A $300 \mathrm{~s}$ cooling period was arbitrarily chosen to allow the main frame and window frame to cool down prior to preparing for the next experiment.

The number of experiments conducted is as follows:

a. A total of 24 experiments were carried out using the $4 \mathrm{~mm}$ thick glass samples glazed with rubber beading, involving 9 experiments with thermocouples attached and 15 experiments without thermocouples attached.

b. A total of 18 experiments were carried out using the $6 \mathrm{~mm}$ thick glass samples glazed with rubber beading, involving 8 experiments with thermocouples attached and 10 experiments without thermocouples attached.

c. A total of 39 experiments were carried out using $4 \mathrm{~mm}$ thick glass samples glazed with ceramic fibre beading, involving 12 experiments with thermocouples attached and 27 experiments without thermocouples attached.

d. A total of 36 experiments were carried out using $6 \mathrm{~mm}$ thick glass samples glazed with ceramic fibre beading, involving 7 experiments with thermocouples attached and 29 experiments without thermocouples attached.

\section{EXPERIMENTAL RESULTS}

Due to the number of glass fallout experiments carried out, only a representative selection are discussed here. According to the radiant heat flux distribution tests, in general the incident heat flux difference between measuring points increased as the average heat flux increased. The differences were normally less than $5 \mathrm{~kW} / \mathrm{m}^{2}$ apart from at Point 1 where a lower heat flux was always obtained leading to a maximum difference of up to $10 \mathrm{~kW} / \mathrm{m}^{2}$ in some cases. The average heat fluxes to the exposed glass surface were determined to be between $13 \mathrm{~kW} / \mathrm{m}^{2}$ and $58 \mathrm{~kW} / \mathrm{m}^{2}$ depending on the distance from the burner to the sample. Figure 4 shows the distribution of the average exposure heat flux conditions. It can be seen in that a majority of the glass samples were subjected to the average heat fluxes ranging from 43 to $47 \mathrm{~kW} / \mathrm{m}^{2}$.

In the experiments with the glass samples glazed with rubber beading, the beading started to smoulder and ignited at a gas temperature reading of approximately $200^{\circ} \mathrm{C}$. The localised burning then spread towards the ends of the rubber beading. The burning of the rubber beading was limited to the edge where the burning of the rubber beading was initiated. In the experiments involving glass samples glazed with ceramic fibre beading, as expected the beading did not ignite or change from its original solid state.

All the glass samples fractured after being exposed to the incident heat flux. Generally, fracture initiated from the edge of the glass and started propagating at an angle away from the edge. The cracks then bifurcated towards the other edges of the glass. Glass samples were observed to have stopped fracturing approximately half-way into each experiment. The mean differences of the average temperatures between the exposed surface and the cold edge were measured as $90{ }^{\circ} \mathrm{C}$ to $98{ }^{\circ} \mathrm{C}$ at the time of glass fracture which is comparable to the $110{ }^{\circ} \mathrm{C}$ fracture temperature difference reported by Shields et al. [9, 10] and the average value of $90^{\circ} \mathrm{C}$ obtained by Skelly et al. [7] for edge-protected window panes. 


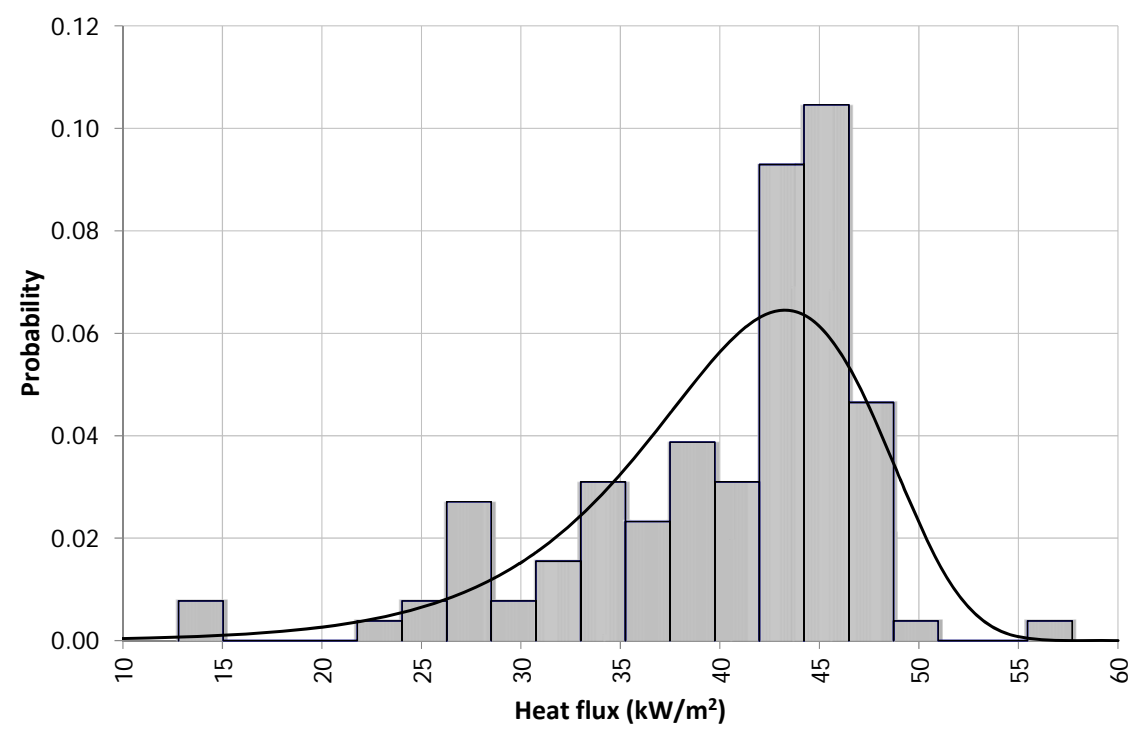

Fig. 4. Distribution of average heat flux data for all experiments.

Although fracturing always occurred, glass fallout did not take place in all experiments. Generally fallout occurred when the bifurcating cracks joined together to form a closed loop although in some experiments the glass stayed in place even after the loop was formed. This situation was more apparent in $6 \mathrm{~mm}$ thick glass samples. In some cases the fallout occurred immediately after fracture while in other cases there was a delay before fallout occurred. As a result, the fallout temperature is found to be as low as the fracture temperature up to $500{ }^{\circ} \mathrm{C}$, compared to the fallout temperature of $447{ }^{\circ} \mathrm{C}$ proposed by Shields et al. [9, 10]. A detailed analysis of the temperature measurements can be found in the main research report [18].

When the tests were terminated it was noted that some cracked glass pieces remained in place within the frame and there was still residual edge glass attached in the window frame in those experiments with fallout reported. Figures $5(\mathrm{a})$ to $5(\mathrm{~d})$ show the final fracture patterns and fallout areas for four selected experiments that displayed fallout behaviour. In the experiments with glass samples glazed with rubber beading, fallouts were recorded in 15 out of 24 experiments involving the $4 \mathrm{~mm}$ thick glass while fallouts were recorded in 5 out of 18 experiments involving the $6 \mathrm{~mm}$ thick glass. In the experiments with glass samples glazed with ceramic fibre beading, fallouts were recorded in 33 out of 39 experiments involving the $4 \mathrm{~mm}$ thick glass samples while fallouts were recorded in 16 out of 36 experiments involving the $6 \mathrm{~mm}$ thick glass samples.

Results from the experiments showed that no fallout occurred below an average heat flux of $20 \mathrm{~kW} / \mathrm{m}^{2}$. This is in line with the findings by Li et al. [19] whose research has shown that a radiant heat flux of only $4-5 \mathrm{~kW} / \mathrm{m}^{2}$ caused glass cracking but did not cause glass fallout. The glass cracking heat flux limit of 4$5 \mathrm{~kW} / \mathrm{m}^{2}$ has also been proposed by Mowrer [20] and it has been widely accepted as a glass fallout criterion. Experimental evidence against this fallout criterion has been found by Shields et al. [9, 10] who have claimed that vent formation due to glass fallout occurs at much higher glass temperatures and heat flux than previously accepted values in the literature. Shields et al. state that for $6 \mathrm{~mm}$ single glazing major glass fallout can only occur at an incident heat flux higher than $35 \mathrm{~kW} / \mathrm{m}^{2}$. The statement has been supported by Manzello et al. [21] using their experiments. In the current study no fallout has been found at heat fluxes lower than $20 \mathrm{~kW} / \mathrm{m}^{2}$ for $4 \mathrm{~mm}$ thick glass and $28 \mathrm{~kW} / \mathrm{m}^{2}$ for $6 \mathrm{~mm}$ thick glass. This finding further supports the $35 \mathrm{~kW} / \mathrm{m}^{2}$ criterion for $6 \mathrm{~mm}$ glass. 


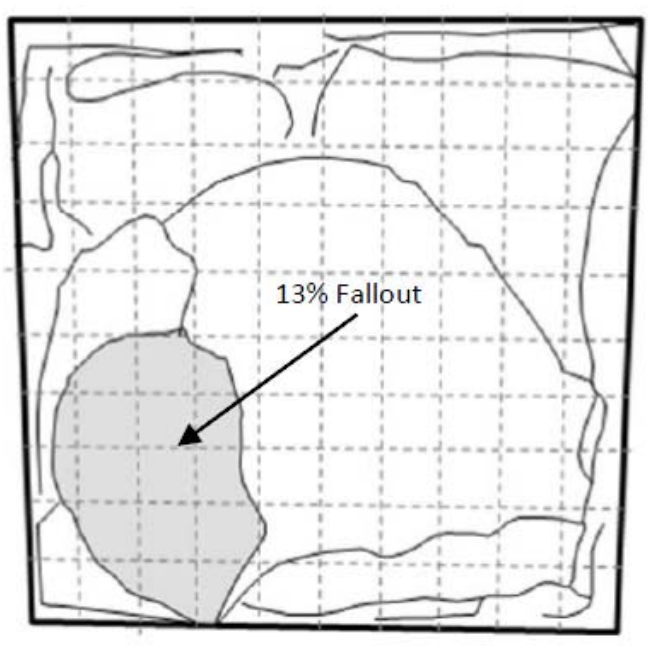

(a)

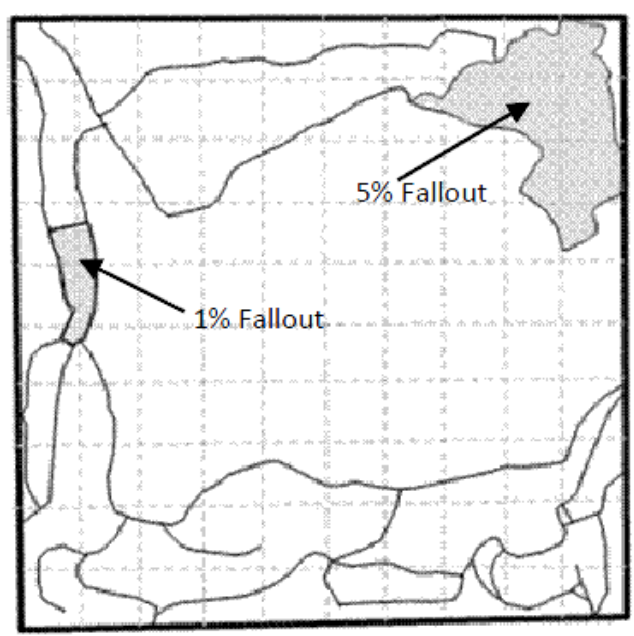

(c)

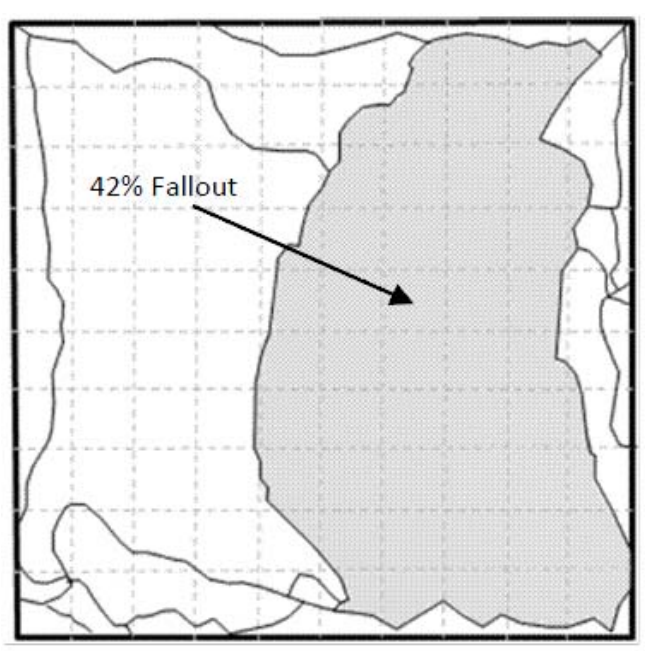

(b)

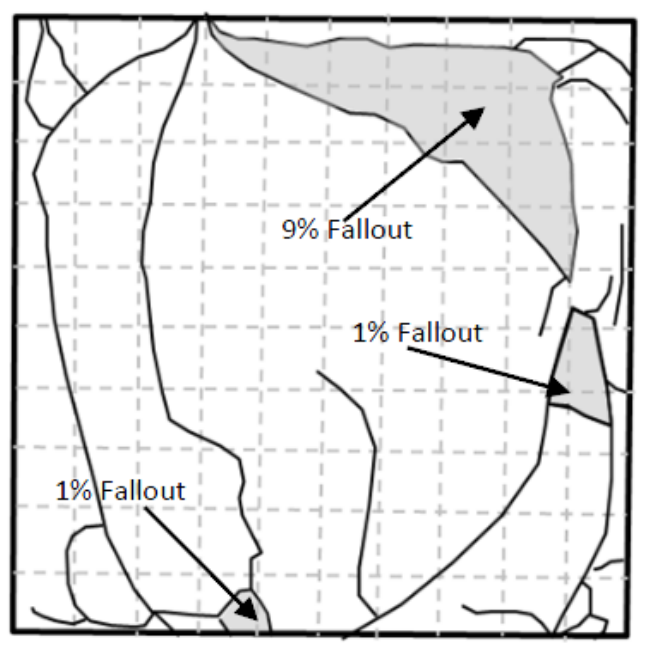

(d)

Fig. 5. Fracture patterns recorded at the end of the test: (a) Test 2 (4 mm glass with rubber beading and thermocouples attached); (b) Test 17 (4 mm glass with ceramic fibre beading and no thermocouple attached); (c) Test 33 (6 mm glass with ceramic fibre beading and thermocouples attached); (d) Test 53

(6 mm glass with rubber beading and no thermocouples attached).

Figures 6(a) to 6(d) present the time histories of the glass fallout experiments without thermocouples attached. It can be seen that in some cases the fallout happens as a single event whereas in others fallout occurs progressively. Compared to the $6 \mathrm{~mm}$ cases, the $4 \mathrm{~mm}$ thick glass samples are more likely to fallout under the same experimental conditions which leads to more experiments with fallout and a relatively larger fallout area. This is understandable as the $6 \mathrm{~mm}$ thick glass is more resilient than the $4 \mathrm{~mm}$ thick glass. The largest fallout area in the $4 \mathrm{~mm}$ cases is $95 \%$ whereas it is $72 \%$ for the $6 \mathrm{~mm}$ cases, however the glass fallout behaves randomly and therefore a probabilistic model has been developed here for glass fallout prediction. 

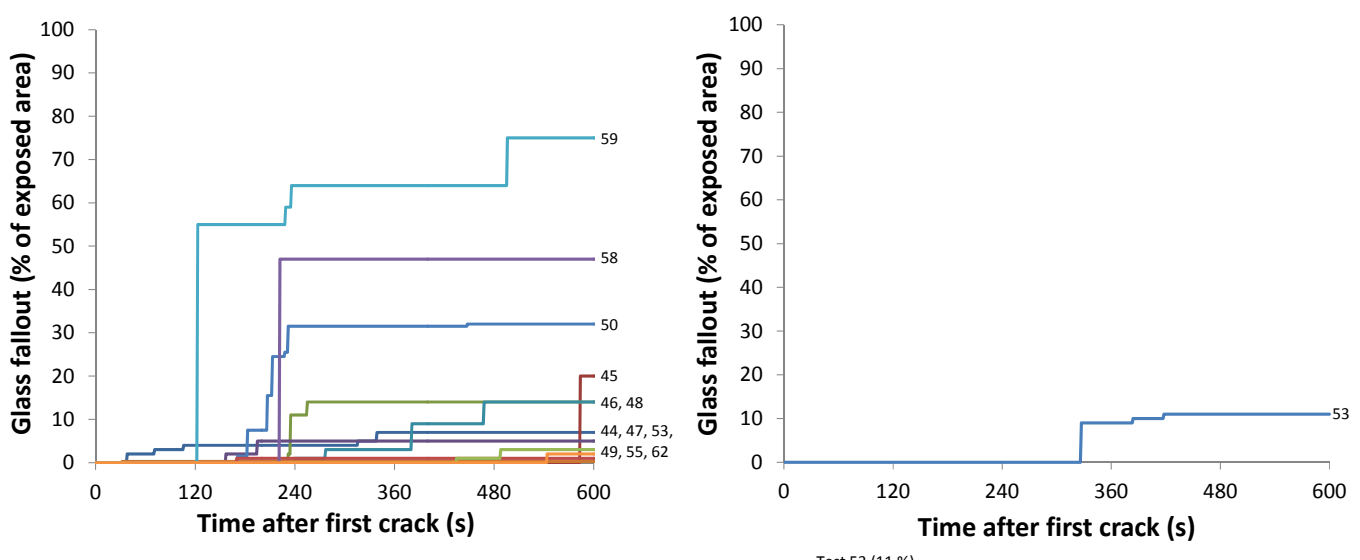

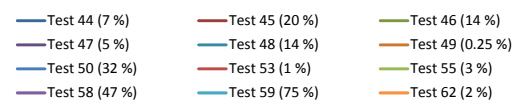

(a)

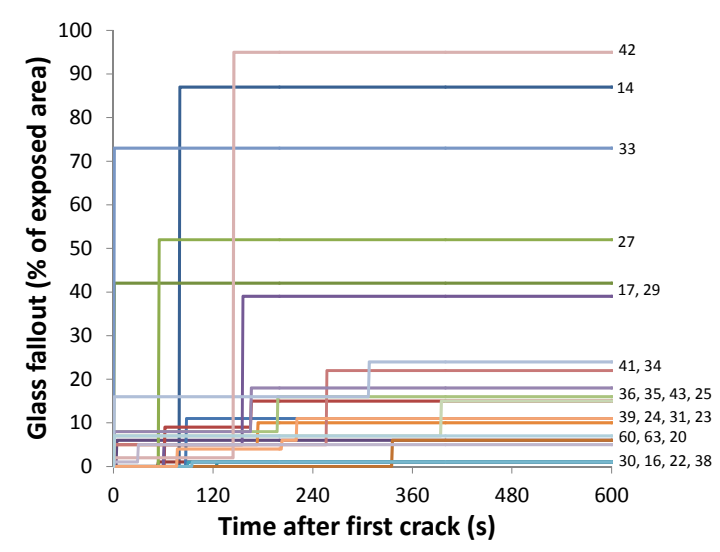

—Test $14(87 \%)$ - Test $16(1 \%)$ — Test $17(42 \%)$ — Test $20(6 \%)$ — Test $22(1 \%)$ —Test $23(6 \%)$ - Test $24(11 \%)$ - Test $25(15 \%)$ —Test $36(18 \%)$ - Test $38(1 \%)$ — Test $39(11 \%)$ - Test $41(24 \%)$ - Test $42(95 \%)$ - Test $43(15 \%)$ — Test $60(5 \%)$ — Test $63(7 \%)$

(c) (b)

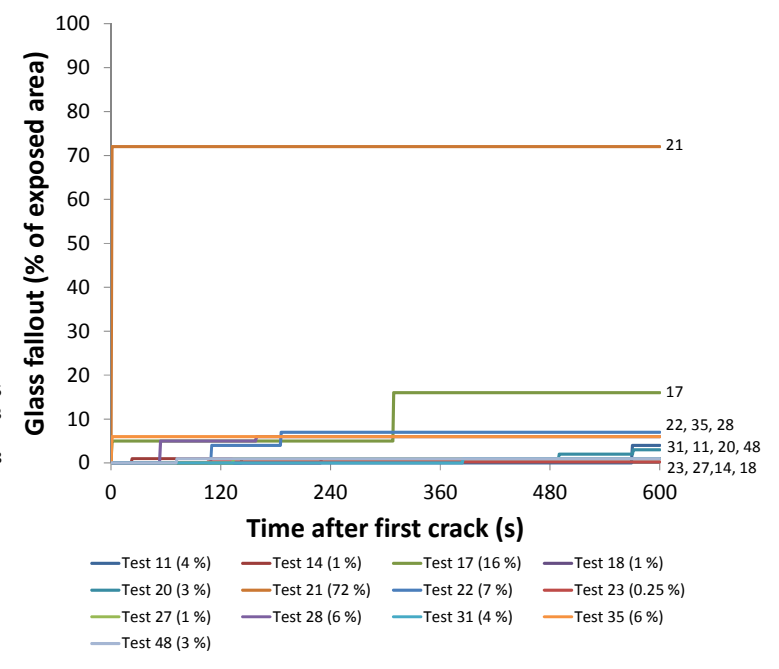

(d)

Fig. 6. Glass fallout time histories without thermocouples attached (Test numbers and final percentage fallout identified for each curve): (a) $4 \mathrm{~mm}$ glass with rubber beading; (b) $6 \mathrm{~mm}$ glass with rubber beading; (c) $4 \mathrm{~mm}$ glass with ceramic fibre beading; (d) $6 \mathrm{~mm}$ glass with ceramic fibre beading.

\section{PROBABILISTIC MODEL FOR GLASS FALLOUT PREDICTION}

The glass fallout prediction model is a probabilistic model using the glass fallout data collected during the experiments. Firstly the experimental data was used to assess the probability that glass fallout would occur after initial fracture. Table 1 includes all the experiments for each given glass thickness to obtain the fallout occurrence probability.

Table 1. Probability of glass fallout occurrence for given thicknesses.

\begin{tabular}{|c|c|}
\hline $\begin{array}{c}\text { Glass thickness } \\
\text { (mm) }\end{array}$ & $\begin{array}{c}\text { Probability of glass } \\
\text { fallout occurrence }\end{array}$ \\
\hline 4 & 0.88 \\
\hline 6 & 0.36 \\
\hline
\end{tabular}


Subsequently analysis of the area of glass fallout data after initial facture is found to have the characteristics of an exponential distribution function. According to Mun [22], this distribution is widely used to describe events that re-occur at random points in time. An example of the application of the exponential distribution is to describe the time between failures of electronic equipment. The exponential probability distribution function is given as:

$$
f(x)=\lambda e^{-\lambda x}
$$

for $x \geqslant 0, \lambda>0$. The cumulative distribution function is given as:

$$
F(x)=1-e^{-\lambda x}
$$

The exponential distribution has the characteristics of the mean $=1 / \lambda$ and the standard deviation $=1 / \lambda$. Thus the parameter $\lambda$ is the only statistic necessary in the distribution function with parameter being the random variable. The cumulative distribution function needs to be described as a descending function since the experiments show that the small area of glass fallouts (if any) are more likely to occur compared with large areas of fallout thus

$$
F(x)=1-\left(1-e^{-\lambda x}\right)
$$

Rearranging Eq. 3 gives

$$
x=-\frac{\ln [F(x)]}{\lambda}
$$

where now $x$ is the potential amount of glass fallout defined as the percentage with respect to the exposed glass area. The final relationship between the potential area of glass fallout and probability of fallout is now given as Eq. 5 where the potential glass fallout area is capped at $100 \%$.

Potential area of glass fallout $(\%)=-\frac{\ln \left\lfloor P_{\text {fallout }}\right\rfloor}{\lambda}$

Thus $P_{\text {fallout }}$ is defined as the probability that a given percentage of the original glass area falls out at a specified time in seconds after the glass has fractured.

The@Risk software [23] was used to obtain $\lambda$ for Eq. 5 where in @Risk, the distribution parameter is defined as the inverse of the continuous scale parameter $\beta$ therefore $\lambda=1 / \beta$ where $\beta>0$. Figures $7(\mathrm{a})$ and 7 (b) show the examples of the glass fallout data that were fitted with the exponential probability distribution curve at selected times of $1 \mathrm{~s}$ and $600 \mathrm{~s}$ after initial fracture. 


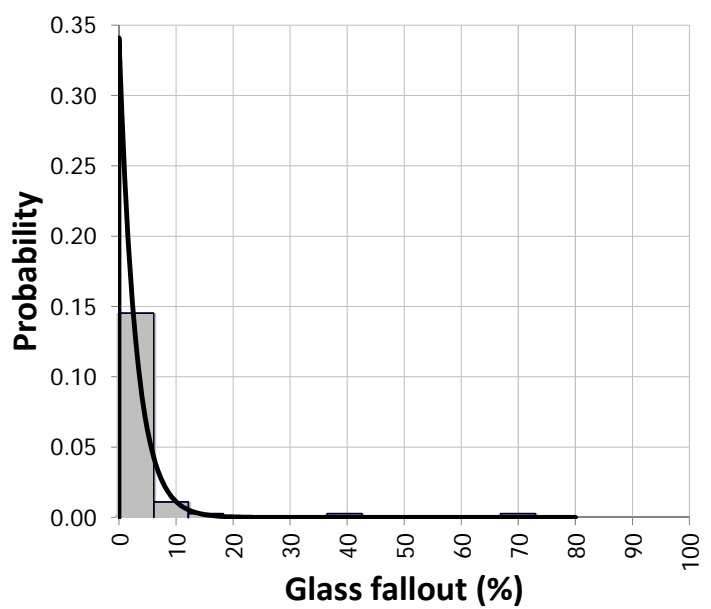

(a)

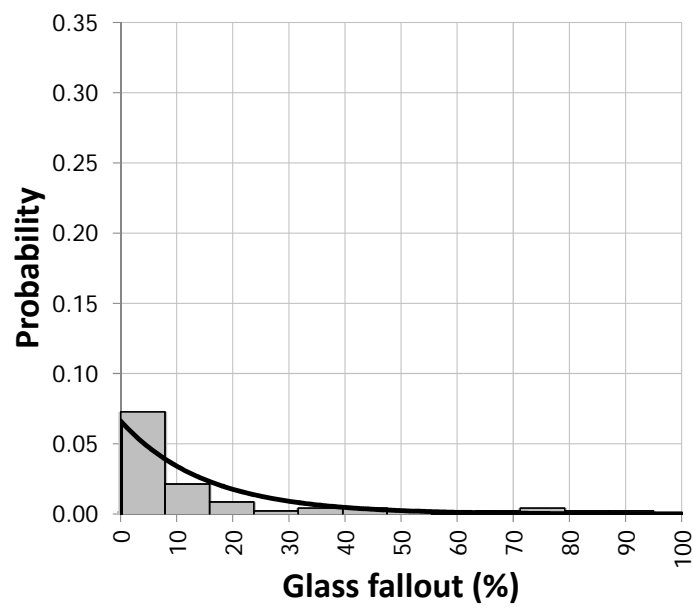

(b)

Fig. 7. Probability exponential distribution curve fitted to glass fallout data from $4 \mathrm{~mm}$ thick glass experiments: (a) $1 \mathrm{~s}$ after glass facture; (b) $600 \mathrm{~s}$ after glass facture.

The respective descending cumulative distribution curves are shown in Figs. 8(a) and 8(b) which describe the probability for the percentage of glass area to fallout at $1 \mathrm{~s}$ and $600 \mathrm{~s}$ after initial glass fracture. At every time step where fallout was reported for a group of experiments with similar characteristics such as those with attached thermocouples, same glass thickness and type of beading, an exponential distribution curve was fitted to the glass fallout data. Examples are shown in Fig. 7(a) and Fig. 7(b) where $\beta=2.93$ and 14.85 respectively and the respective $\lambda$ values are calculated to be 0.341 and 0.067 . A trend line was fitted to the plots of $\lambda$ against time after initial fracture and an equation function describing the trend line was obtained through the data as shown in Fig. 9.

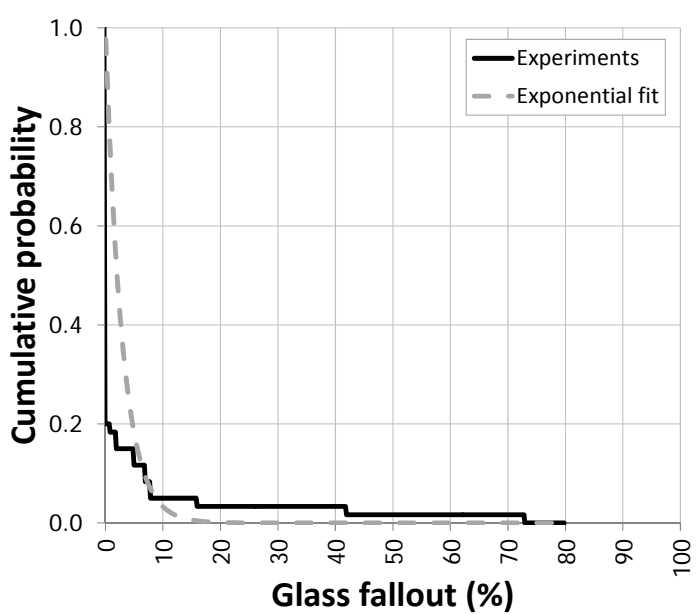

(a)

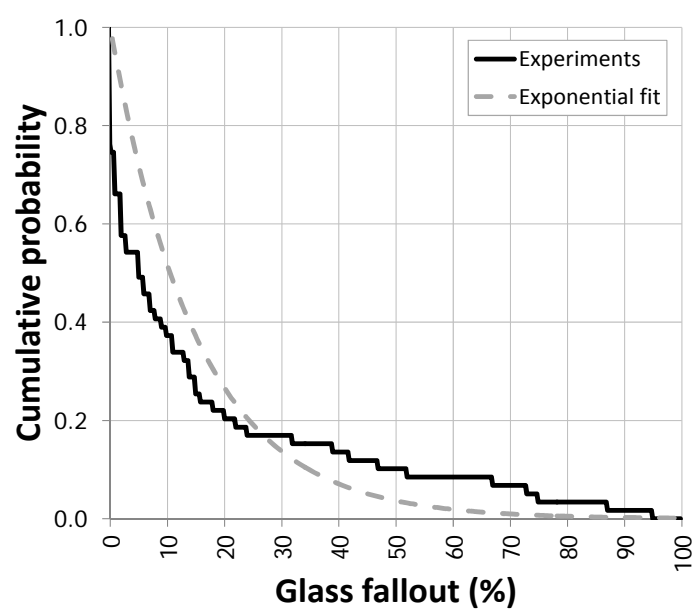

(b)

Fig. 8. Descending cumulative exponential distribution curve fitted to glass fallout data from all $4 \mathrm{~mm}$ thick glass experiments: (a) $1 \mathrm{~s}$ after glass facture; (b) $600 \mathrm{~s}$ after glass facture. 


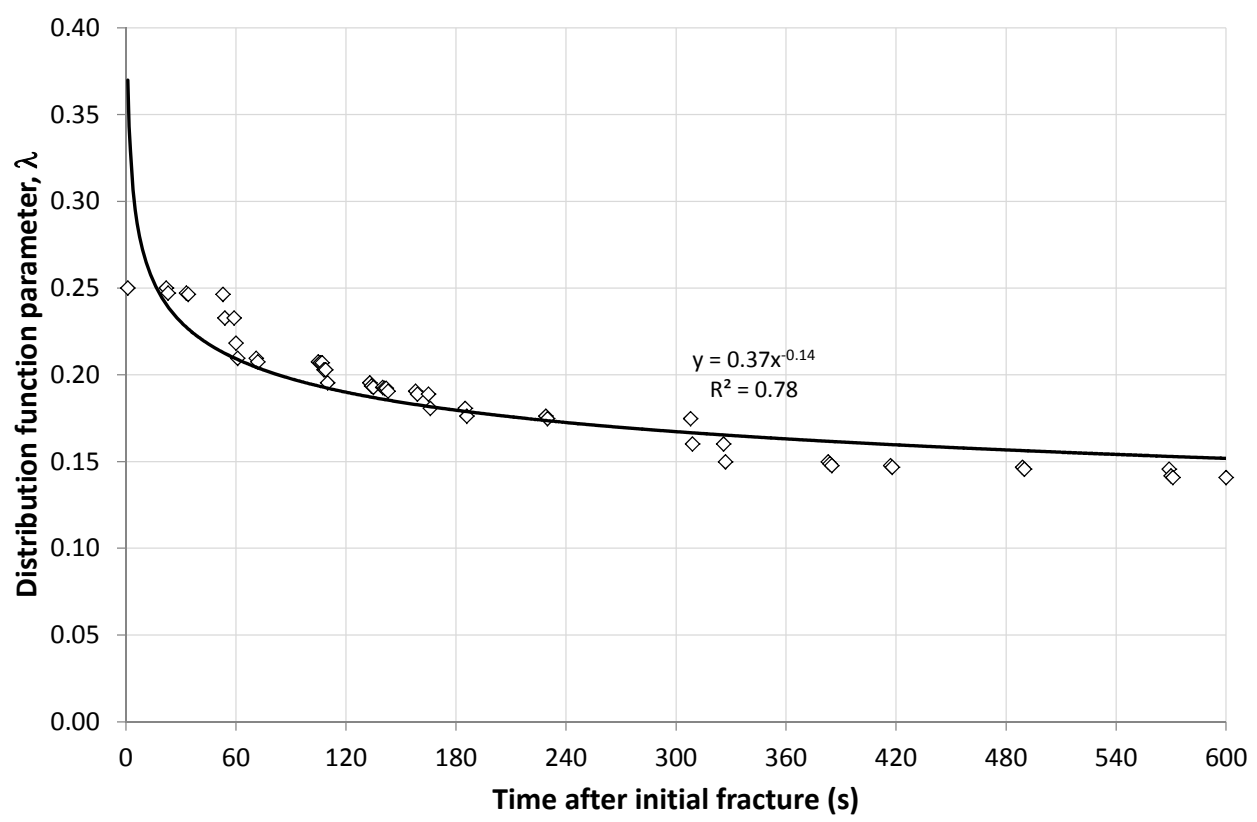

Fig. 9. Distribution function parameter for $6 \mathrm{~mm}$ thick samples with glass fallout.

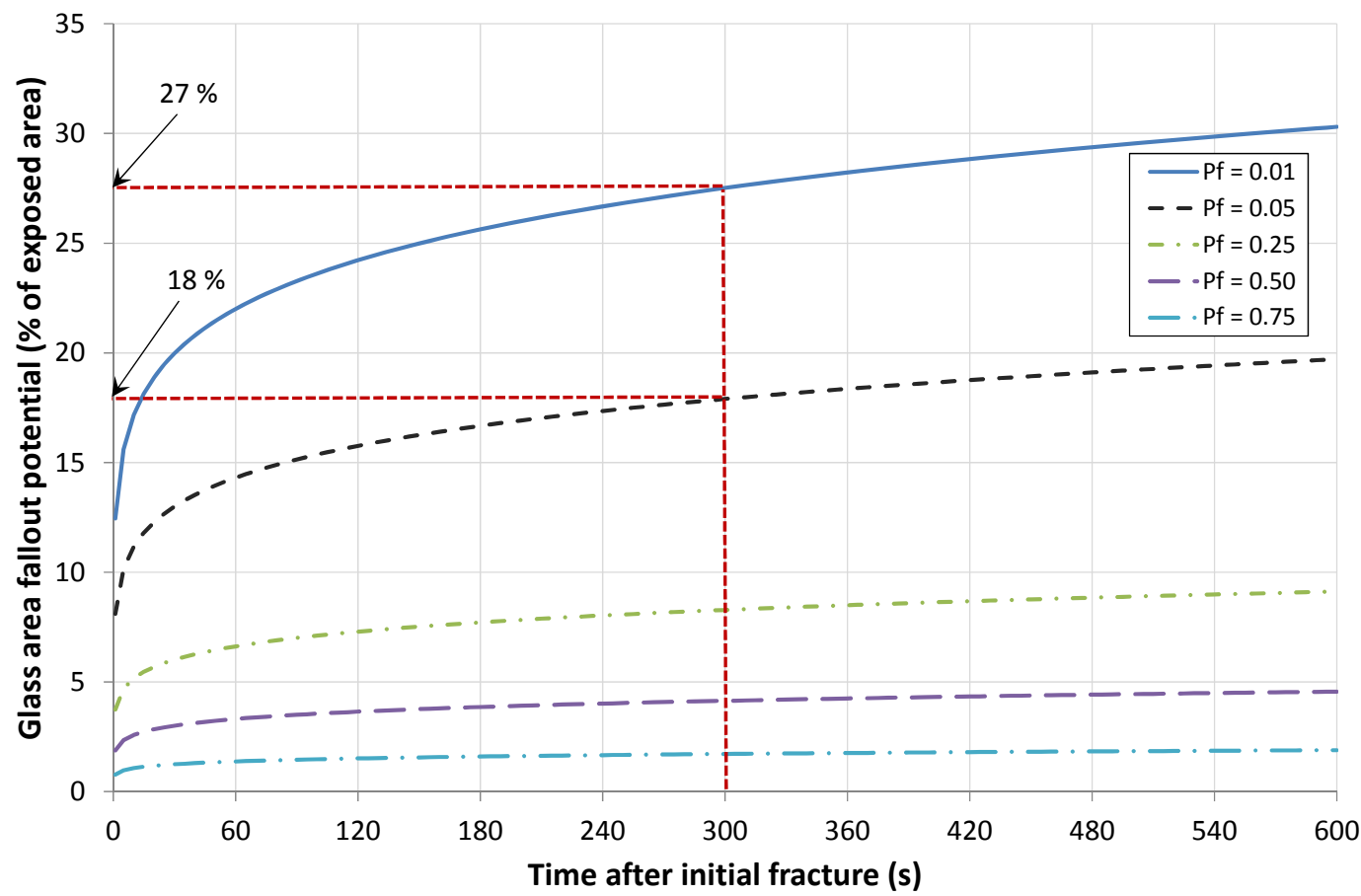

Fig. 10. Potential glass fallout area using $6 \mathrm{~mm}$ thick samples in which fallout occurred.

The general equation for the probabilistic model for glass fallout prediction can be expressed as Eq. 6 where $t_{1} \leq 600 \mathrm{~s}$.

Potential area of glass fallout $(\%)=\operatorname{Min}\left(-\frac{\ln \left[P_{\text {fallout }}\right] t_{1}^{a_{1}}}{b_{1}}, 100\right)$ 
where $a_{1}$ and $b_{1}$ are the parameters are determined using the experimental data. A plot of the potential glass fallout with respect to the probability of $6 \mathrm{~mm}$ glass fallout is shown in Fig. 10 where the label "Pf" is the probability of fallout, $P_{\text {fallout }}$. Hence once the parameters $a_{1}$ and $b_{1}$ are determined using Eq. 6 the percentage area of glass fallout can be provided as a probability of fallout $\left(P_{\text {fallout }}\right)$ at any time during a fire scenario. For example, the probabilities of around $27 \%$ and $18 \%$ of the original area of glass fallout occurring at $300 \mathrm{~s}$ are 0.01 and 0.05 respectively.

Results from the experiments and subsequent analysis suggest the type of beading and the presence of the thermocouples have no major impact on the exponential distribution function fitting parameters. Therefore to enable a sufficiently large statistical sample in the analysis, all of the experiments for a given glass thickness were used in the area of glass fallout prediction model. The fitting parameters from results for only those experiments which exhibited fallout are shown in Table 2 . These parameters are only applicable to fallout predictions in those cases with a heat flux being greater than $20 \mathrm{~kW} / \mathrm{m}^{2}$ for $4 \mathrm{~mm}$ thick glass and $28 \mathrm{~kW} / \mathrm{m}^{2}$ for $6 \mathrm{~mm}$ thick glass.

Table 2. Parameters for area of glass fallout prediction model, Eq. 6.

\begin{tabular}{|c|c|c|}
\hline $\begin{array}{c}\text { Glass thickness } \\
\text { (mm) }\end{array}$ & $\boldsymbol{a}_{\mathbf{1}}$ & $\boldsymbol{b}_{\mathbf{1}}$ \\
\hline 4 & 0.400 & 0.560 \\
\hline 6 & 0.097 & 0.239 \\
\hline
\end{tabular}

To use the area of glass fallout prediction model in practical designs, numerical simulations in the form of a computer program (e.g. B-RISK) can be used to carry out the heat transfer analysis to determine the time to glass fracture. In the absence of a computer program, the heat transfer analysis can be carried out manually and the time to glass facture can also be determined. It should be noted that the probability of glass fallout $\left(P_{\text {fallout }}\right)$ in the glass prediction model should not be taken directly from Table 1 as the probability of glass fallout occurrence is based on the fallout data from the experiments irrespective of the area of fallout.

\section{CONCLUSIONS}

Glass panes in $500 \mathrm{~mm}$ square aluminium frames were exposed to radiant heat fluxes ranging from $13 \mathrm{~kW} / \mathrm{m}^{2}$ to $58 \mathrm{~kW} / \mathrm{m}^{2}$. Fracture of the glass was observed in all of the experiments although this did not necessarily result in any fallout. It is found that the lowest heat fluxes needed for fallout occurrence are $20 \mathrm{~kW} / \mathrm{m}^{2}$ for $4 \mathrm{~mm}$ thick glass and $28 \mathrm{~kW} / \mathrm{m}^{2}$ for $6 \mathrm{~mm}$ thick glass.

Generally, when fallout behaviour was observed it did not occur immediately after the initial fracture and the area and progression of fallout was variable. Regardless of the type of beading there was still residual edge glass attached in the window frame so that the total area of fallout was never $100 \%$. At a given heat flux the occurrence of fallout was less likely and area of fallout was lesser for the $6 \mathrm{~mm}$ thick glass as compared to the $4 \mathrm{~mm}$ thick material.

The fallout area behaviour of single glazed float glass as a function of time is described with an exponential distribution function and a prediction model is derived for the $4 \mathrm{~mm}$ and $6 \mathrm{~mm}$ thick samples. The model is probabilistic and it can be used for predicting the potential glass fallout area at a heat flux being greater than a fallout occurrence limit. However, the application of the model is subject to the limitations imposed by the experimental conditions.

Given the limitations of the current study there are many opportunities for further work. Recommended work includes experiments on larger windows, different frame materials and shapes, other types of glass and the effect of multiple layers of glazing. It would also be beneficial to consider a condition where there is pressure acting on the glass. A source of pressure could be the expanding air in the compartment due to the fire and/or an external wind. Furthermore a compartment would also induce a "layering effect" where non-uniform heating that will induce a vertical thermal gradient on the glass which could then influence the fallout characteristics.

Results from this study could be used as a comparison with the model developed by Hietaniemi and either this model or the much simpler one proposed here could be incorporated into a future release of B-RISK. 


\section{ACKNOWLEDGEMENTS}

The authors would like to thank Grant Dunlop and Bob Wilsea-Smith for constructing the rig and assisting with the experiments. The research was partially supported by the previously existing Foundation for Research, Science and Technology programme granted through BRANZ Ltd and the Chinese Universities Scientific Fund (CUSF) No. WK2320000017.

\section{REFERENCES}

[1] Emmons, H.W., (1986) The Needed Fire Science. Fire Safety Science 1: 33-53. http://dx.doi.org/10.3801/IAFSS.FSS.1-33

[2] Ji, J., Li, L. J., Shi, W. X., Fan, C. G. and Sun, J. H., (2013) Experimental investigation on the rising characteristics of the fire-induced buoyant plume in stairwells, International Journal of Heat and Mass Transfer 64:193-201, http://dx.doi.org/10.1016/j.ijheatmasstransfer.2013.04.030

[3] Cuzzillo, B. R., and Pagni, P. J., (1998) Thermal Breakage of Double-pane Glazing by Fire, Journal of Fire Protection Engineering 9(1): 1-11, http://dx.doi.org/10.1177/104239159800900101

[4] Li, L. J., Ji, J., Fan, C. G. and Sun, J. H., (2013) Experimental investigation on the characteristics of buoyant plume movement in a stairwell with multiple openings, Energy and Buildings, http://dx.doi.org/10.1016/j.enbuild.2013.09.028

[5] Babrauskas, V., Glass Breakage in Fires, www.doctorfire.com/glass.html, Accessed $2^{\text {nd }}$ March 2010.

[6] Keski-Rahkonen, O., (1988) Breaking of Window Glass Close to Fire, Fire and Materials 12(2): 61-69, http://dx.doi.org/10.1002/fam.810120204

[7] Skelly, M. J., Roby, R. J., and Beyler, C. L., (1991) An Experimental Investigation of Glass Breakage in Compartment Fires, Journal of Fire Protection Engineering 3(1): 25-34, http://dx.doi.org/10.1177/104239159100300103

[8] Harada, K., Enomoto, A., Uede, K., and Wakamatsu, T., (2000) An Experimental Study on Glass Cracking and Fallout by Radiant Heat Exposure. Fire Safety Science 6: 1063-1074. http://dx.doi.org/10.3801/IAFSS.FSS.6-1063

[9] Shields, T. J., Silcock, G. W. H., and Flood, M. F., (2001) Performance of a Single Glazing Assembly Exposed to Enclosure Corner Fires of Increasing Severity, Fire and Materials 25(4): 123-152, http://dx.doi.org/10.1002/fam.764

[10] Shields, T. J., Silcock, G. W. H., and Flood M., (2002) Performance of a Single Glazing Assembly Exposed to a Fire in the Centre of an Enclosure, Fire and Materials 26(2): 51-75, http://dx.doi.org/10.1002/fam.783

[11] Pope, N. D., and Bailey, C. G., (2007) Development of a Gaussian Glass Breakage Model within a Fire Field Model, Fire Safety Journal 42(5): 366-376, http://dx.doi.org/10.1016/j.firesaf.2006.12.005

[12] Parry, R., Wade, C. A., and Spearpoint, M., (2003) Implementation of a Glass Fracture Module for BRAZNFIRE Zone Model, Journal of Fire Protection Engineering 13(3): 157-183 http://dx.doi.org/10.1177/1042391503033366

[13] Sincaglia, P. E., and Barnett J. R., (1997) Development of a Glass Window Fracture Model for Zone-Type Computer Fire Codes, Journal of Fire Protection Engineering 8(3): 101-118, http://dx.doi.org/10.1177/104239159600800301

[14] Pagni, P.J., and Joshi, A.A., (1991) Glass Breaking in Fires. Fire Safety Science 3: 791-802. http://dx.doi.org/10.3801/IAFSS.FSS.3-791

[15] Wade, C. A., "BRANZFIRE Technical Reference Guide,” BRANZ Study Report 92, Building Research Association of New Zealand, Judgeford, New Zealand, 2000. 
[16] Wade, C., Baker, G., Frank, K., Robbins, A., Harrison, R., Spearpoint, M., and Fleischmann, C., "B-RISK User Guide and Technical Manual," BRANZ Study Report No 282. BRANZ Ltd., Judgeford, New Zealand, 2013.

[17] Hietaniemi, J., "Probabilistic Simulation of Glass Fracture and Fallout in Fire," VTT Working Papers 41, VTT Building and Transport, Finland, 2005.

[18] Wong, D. L. W., “The Fallout of Single Glazing under Radiant Heat Exposure," Master's Project Report, University of Canterbury, Christchurch, New Zealand, 2011.

[19] Li, L. M., Xie, Q. Y., Cheng, X. D., and Zhang, H. P., (2012) Cracking Behavior of Glazings with Different Thicknesses by Radiant Exposure, Fire and Materials 36(4): 264-276, http://dx.doi.org/10.1002/fam.1108

[20] Mowrer, F. W., "Window Breakage Induced by Exterior Fires," NIST-GCR-98-751, National Institute of Standards and Technology, Gaithersburg, MD, USA, 1998.

[21] Manzello, S. L., Kukuck, S. R., Prasad, K. R., and Jones, W. W., (2007) An Experimental Determination of a Real Fire Performance of a Non-Load Bearing Glass Wall Assembly, Fire Technology 43(1): 77-89, http://dx.doi.org/10.1007/s10694-006-0001-5

[22] Mun, J., Modeling Risk: Applying Monte Carlo Simulation, Real Options Analysis, Forecasting, and Optimization Techniques, John Wiley \& Sons Inc, USA, 2006, 480 p.

[23] Palisade Corporation, “@Risk The Decision Tools Suite version 5.5.0,” Industrial Edition, New York, 2009. 